\title{
Behavioral and spermatogenic hybrid male breakdown in Nasonia
}

\author{
ME Clark, FP O'Hara ${ }^{1}$, A Chawla ${ }^{2}$ and JH Werren \\ Department of Biology, University of Rochester, Rochester, NY, USA
}

\begin{abstract}
Several reproductive barriers exist within the Nasonia species complex, including allopatry, premating behavioral isolation, postzygotic inviability and Wolbachia-induced cytoplasmic incompatibility. Here we show that hybrid males suffer two additional reproductive disadvantages, an inability to properly court females and decreased sperm production. Hybrid behavioral sterility, characterized by a reduced ability of hybrids to perform necessary courtship behaviors, occurs in hybrids between two species of Nasonia. Hybrid males produced in crosses between $N$. vitripennis and $N$. giraulti courted females at a reduced frequency (23-69\%), compared with wild-type $N$. vitripennis and $N$. giraulti males (>93\%). Reduced courtship frequency was not a simple function of inactivity among hybrids. A strong effect of cytoplasmic (mitochondrial) background was also found in $N$. vitripennis and $N$. giraulti crosses;
\end{abstract}

F2 hybrids with giraulti cytoplasm showing reduced ability at most stages of courtship. Hybrids produced between a younger species pair, $N$. giraulti and $N$. Iongicornis, were behaviorally fertile. All males possessed motile sperm, but sperm production is greatly reduced in hybrids between the older species pair, $N$. vitripennis and $N$. giraulti. This effect on hybrid males, lowered sperm counts rather than nonfunctional sperm, is different from most described cases of hybrid male sterility, and may represent an earlier stage of hybrid sperm breakdown. The results add to previous studies of F2 hybrid inviability and behavioral sterility, and indicate that Wolbachia-induced hybrid incompatibility has arisen early in species divergence, relative to behavioral sterility and spermatogenic infertility.

Heredity (2010) 104, 289-301; doi:10.1038/hdy.2009.152; published online 20 January 2010

Keywords: Nasonia; courtship behavior; spermatogenesis; hybrid sterility; speciation

\section{Introduction}

Since the emergence of the Biological Species concept (Dobzhansky, 1935, 1937; Mayr, 1942), research on speciation has focused largely on the role of reproductive isolation in generating and maintaining biological diversity. Significant theoretical and experimental research has focused on postzygotic reproductive isolation, the reduced fitness of hybrid offspring. Hybrid unfitness is typically described in the form of hybrid inviability and hybrid sterility, phenomena that have been characterized in a wide variety of taxa (Dobzhansky, 1937). For logistic and technical reasons, hybrid inviability is normally measured as a reduction in the number of offspring produced, and hybrid sterility is measured by the absence of motile sperm or the inability of hybrids to produce offspring. In addition to these hybrid maladies, several ecological and behavioral aspects of hybrid unfitness have been reported (Coyne and Orr, 2004).

One form of postzygotic ecological isolation occurs when surviving hybrids are maladapted to available niches because they have intermediate phenotypes

Correspondence: Dr ME Clark, Department of Biology, University of Rochester, Hutchison Hall, Rochester, NY 14627, USA.

E-mail: mclark11@mail.rochester.edu

${ }^{1}$ Current address: Computational Biology, GlaxoSmithKline, Collegeville, PA 19426, USA

${ }^{2}$ Current Address: Department of Surgery, University of Rochester Medical Center, Rochester, NY 14627, USA.

Received 4 May 2009; revised 19 August 2009; accepted 18 September 2009; published online 20 January 2010
(Schluter, 2001). For example, this appears to occur in hybrid stickleback fishes (Schluter, 1995; Hatfield and Schluter, 1999) and in Darwin's finches (Grant and Grant, 1992). In addition, the interaction between environment and hybrid genotype has been studied in a number of plants (Arnold, 1997). Other recent studies reveal that postzygotic reproductive isolation can also involve defects in hybrid courtship behavior. Hybrid behavioral sterility occurs when hybrids are unable to perform courtship behaviors (Pashley and Martin, 1987; Price and Boake, 1995; Davies et al., 1997; Noor, 1997; Coyne et al., 2003), or perform courtship behaviors that are unattractive to individuals of either parent species (Stratton and Uetz, 1986; Hatfield and Schluter, 1996; Vamosi and Schluter, 1999).

Postzygotic reproductive isolation can also manifest in the form of reductions in hybrid fertility because of defects in gametogenesis. Several genes have recently been identified as having likely roles in hybrid sterility. These include Odysseus, a rapidly evolving homeoboxcontaining gene important in male sterility in Drosophila simulans-D. mauritiana hybrids (Ting et al., 1998), JYAlpha, a gene that encodes a subunit of an ion exchange complex and whose transposition has led to hybrid male sterility in D. melanogaster-D. simulans hybrids (Masly et al., 2006). Overdrive, responsible for both hybrid sterility and segregation distortion among subspecies of $D$. pseudoobscura, (Phadnis and Orr, 2009), and Prdm9, a gene coding a meiotic histone methyltransferase, contribute to spermatogenic breakdown in Mus musculus musculus-M. musculus domesticus hybrids (Mihola et al., 2008). 
Much work on hybrid sterility concerns large effects resulting in a complete breakdown of spermatogenesis and nonfunctional or absent sperm. Few studies have addressed more subtle effects on hybrid sperm production that may occur earlier in the speciation process. Among hybrids of $M$. musculus and M.domesticus species and subspecies, reduced sperm production is a significant contributor to the reduction in hybrid male fertility (Good et al., 2008).

Little is known about the molecular basis of hybrid behavioral sterility. Possible causes of hybrid behavioral sterility fall into three basic classes. First, hybrids may suffer from generalized malaise, for example, defects of biochemical or physiological systems that also impair an organism's ability to perform complex functions (Yamamoto et al., 1997). Second, hybrids may exhibit intermediate or mixed courtship behaviors that reduce mating success with both parent species (Stratton and Uetz, 1986; Hatfield and Schluter, 1996; Vamosi and Schluter, 1999). Third, hybrid courtship could be disrupted by negative epistatic interactions between courtship-specific genes. This possibility is analogous to the negative epistatic interactions proposed to cause hybrid inviability and spermatogenic sterility. That is, genes that influence courtship behavior within species can interact negatively in hybrids to result in disruption or ablation of one or more components of the behavior. Existing data from the few studies of hybrid behavioral sterility do not yet allow for conclusions to be drawn about the relative frequencies of the three types.

We describe here new examples of hybrid sterility in the parasitic wasp genus Nasonia. Nasonia has already been the focus of a number of studies of behavior (van den Assem and Werren, 1994; Jachmann and van den Assem, 1996) and reproductive isolation (Breeuwer and Werren, 1990, 1995). We studied hybrid breakdown between two different pairs of species (one older and one younger pair) by measuring the behavioral and spermatogenic fertility of hybrid males. In general, research on insect speciation indicates that hybrid gametogenic sterility, especially in heterogametic males, evolves relatively quickly compared with hybrid inviability and other forms of hybrid breakdown ( $\mathrm{Wu}$ and Davis, 1993; Coyne and Orr, 1998). We find that both hybrid male behavioral sterility and hybrid spermatogenic sterility (reduced sperm production) occur in Nasonia. Our results are consistent with the sexual selection hypothesis for evolution of hybrid sterility (Wu and Davis, 1993), which proposes that hybrid incompatibilities are caused by interactions between genes that are rapidly evolving in isolated populations because of selection acting on reproductive characters.

Among the four species of Nasonia, courtship behavior has diverged significantly. Although each of the species shares most aspects of courtship behaviors, each differs in the timing, duration and frequency of different courtship components, making it an attractive model for studying the genetic basis of courtship evolution (van den Assem and Werren, 1994; Beukeboom and van den Assem, 2001, 2002). The mating behavior of longicornisvitripennis hybrid males has been previously studied. These hybrid males easily court and exhibit intermediate courtship phenotypes, which are biased toward the phenotype of the grandpaternal species (Beukeboom and van den Assem, 2001, 2002).
Several aspects of Nasonia biology make it an appealing system for studying spermatogenesis and hybrid male fertility. In Nasonia, post-copulatory behavior by males greatly reduces female receptivity to future mating, making multiple matings by females uncommon and sperm competition relatively unimportant in this system (Whiting, 1967; Leonard and Boake, 2008). Males are haploid, making genetic investigations straightforward without complications from dominance. Spermatogenesis in Nasonia is similar to that of diploid insects with one important exception. As Nasonia males are haploid, meiosis cannot proceed normally. Meiosis I is aborted and meiosis II is normal (Pennypacker, 1958). The resulting sperm are genetically identical. It is unclear how this functionally ameiotic spermatogenesis might affect reproductive isolation.

Nasonia lacks chromosomal sex determination, and therefore Haldane's rule cannot be strictly applied in this system. However, an understanding of the genetic basis of hybrid unfitness in Nasonia may serve as valuable tests for competing theories explaining the genetic basis behind speciation patterns described by Haldane's rule (Koevoets and Beukeboom, 2009).

Behavioral sterility among Nasonia species has been previously reported (Bordenstein et al., 2001). Here, we expand on those original findings by including a detailed examination of each stage of courtship and for each reciprocal cross among all three species. Similarly, Bordenstein et al. (2001) report little or no spermatogenic sterility among the Nasonia species. We conducted a detailed analysis of spermatogenesis, and detected both reductions in sperm production and defects in spermatogenesis. Comparisons of findings and methods with this earlier study are presented.

\section{Materials and methods}

\section{Biology of Nasonia}

Nasonia is a genus of four closely related parasitoid wasp species (Whiting, 1967; Darling and Werren, 1990). N. vitripennis (hereafter vitripennis) is a cosmopolitan generalist, whereas $N$. longicornis (longicornis) and N. giraulti (giraulti) specialize on the pupae of Calliphorid flies in the western and eastern USA, respectively. Giraulti and longicornis are allopatric, but the range of each is imbedded within the range of vitripennis (Darling and Werren, 1990). A new species, N. oneida, has recently been described and is not addressed in this report (Raychoudhury et al., 2009). Like nearly all Hymenopterans, Nasonia has a haplodiploid sex-determining system. Males are haploid and develop from unfertilized eggs and females are diploid and develop from fertilized eggs. Vitripennis and giraulti are isolated by a number of mechanisms including partial, asymmetric sexual isolation (Bordenstein et al., 2000), Wolbachia-induced cytoplasmic incompatibility (CI) (Breeuwer and Werren, 1990) and partial F2 breakdown of viability (Breeuwer and Werren, 1995). F1 hybrid females are normally rare or absent in crosses among Nasonia species because of the activity of Wolbachia, but can be easily produced after curing strains of their bacteria (Breeuwer and Werren, 1990), and F1 female hybrids are viable and fertile. According to mitochondrial and ITS2 sequence data 
(Campbell et al., 1993), the divergence of the Nasonia species occurred between 0.2 and 1 myr. Giraulti and longicornis are the more closely related species, having separated after divergence from their common ancestor with vitripennis (Figures 1 and 2). Therefore, in this genus, we have the opportunity to study the evolution of reproductive isolation between species that are all relatively young, and that differ in their stages of divergence and reproductive isolation.

The normal courtship behavior of Nasonia species has been previously described (van den Assem and Werren, 1994; Jachmann and van den Assem, 1996). We summarize some important aspects here (Table 1). Courtship begins when a male locates and briefly follows a female. After catching the female, the male mounts the female's dorsal side. At this time, the female's movement is arrested and the male orients his head over the female's head. A ritualized courtship display is then performed. The display is cyclic, and each cycle consists of stereotyped motions, including antennal sweeps, head nods, wing vibrations and mouthpart extrusions. The different species of Nasonia differ in the duration of the display cycles, and in other details of the display. Courtship cycles are associated with the release of pheromones necessary to induce female receptivity.
A virgin female will normally become receptive to the first conspecific male that courts her. She signals receptivity by dropping her antennae (Jachmann and van den Assem, 1996). After the female signals receptivity, the male backs up and copulates. Females typically mate only once, and when multiple mating occurs, first male sperm precedence normally occurs (Holmes, 1974; van den Assem et al., 1980b).

Spermatogenesis is largely synchronized in Nasonia. Males are relatively short lived but can mate with great rapidity immediately on eclosion. Most sperm production is complete at eclosion. Within a normal pupal testis, most of the developing spermatocysts are at the same, or similar, developmental stages (Pennypacker, 1958; Clark et al., 2008). As a result, Nasonia is a tractable system for investigating differences in the timing or magnitude of sperm production.

\section{Strains and crosses}

Wasps were reared under conditions of constant light and temperature $\left(25^{\circ} \mathrm{C}\right)$ and developed on fresh Sarcophaga bullata fly pupae. Generation time under these conditions is approximately 14 days for vitripennis and 15 days for giraulti and longicornis. Hybrids can have

a
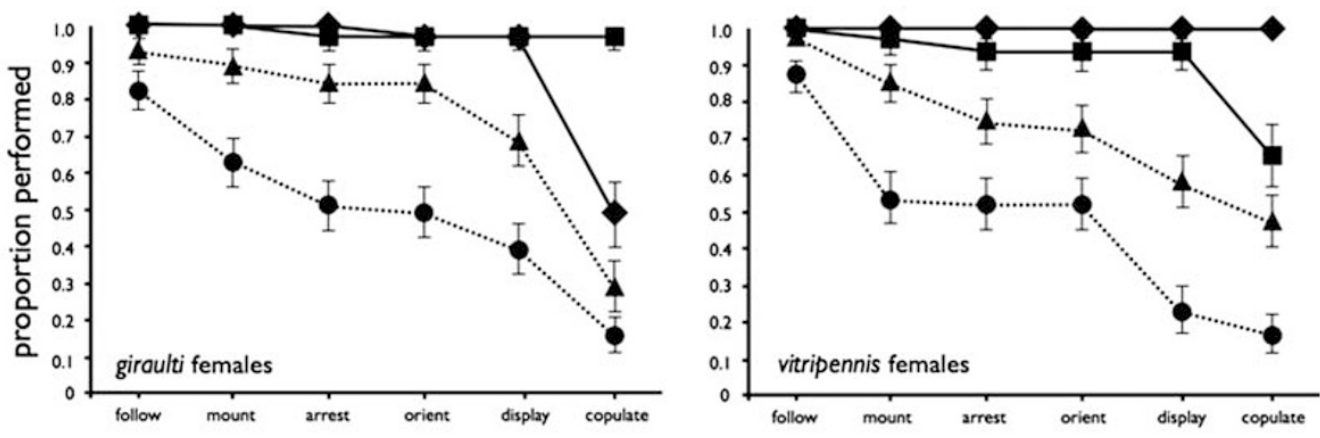

b

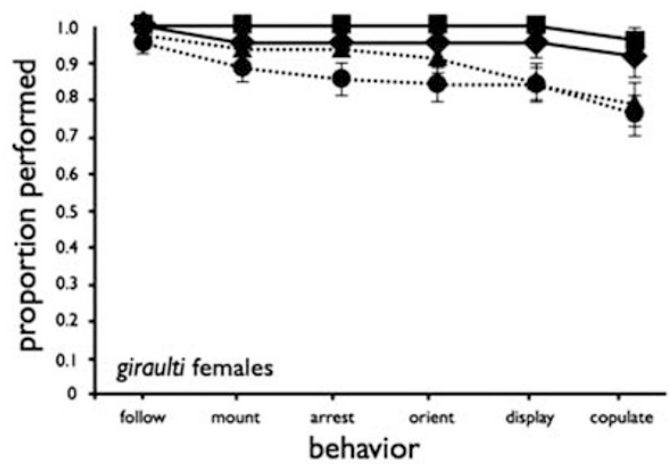

arrest

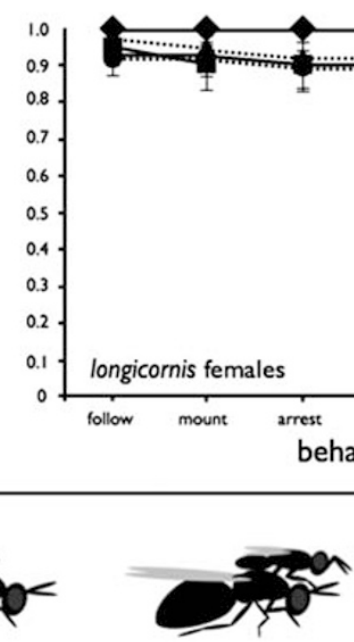

orient

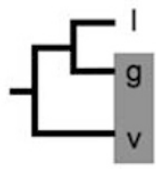

male genotype

a $\mathrm{g}$

$\checkmark v$

$\Delta \mathrm{g} / \mathrm{v}[\mathrm{v}]$

$\bullet g / v[g]$

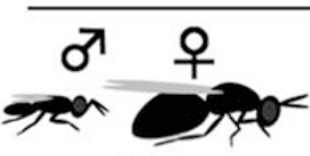

follow

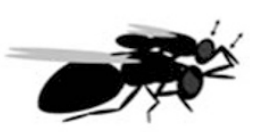

display

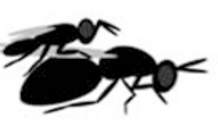

mount

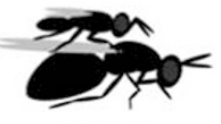
of the six stages of courtship behavior are plotted, with the sequential order
(right). (b) of courtship stages along the $x$ axis. (a) Older species pair (vitripennis-giraulti) using giraulti females (left) and vitripennis females (right). (b) Younger species (giraulti-longicornis) pairing giraulti females (left) and longicornis females (right). Courtship behaviors are shown (bottom) and described in Table 1. Standard deviations for proportions were obtained by transforming proportions into angles $(\theta)$ through the arcsine square-root transformation. Variances of the angles were then calculated and used to determine standard deviations of $\theta$. Standard deviations were then back-transformed to give values in proportions for visual presentation. Error bars $=1$ s.d. 


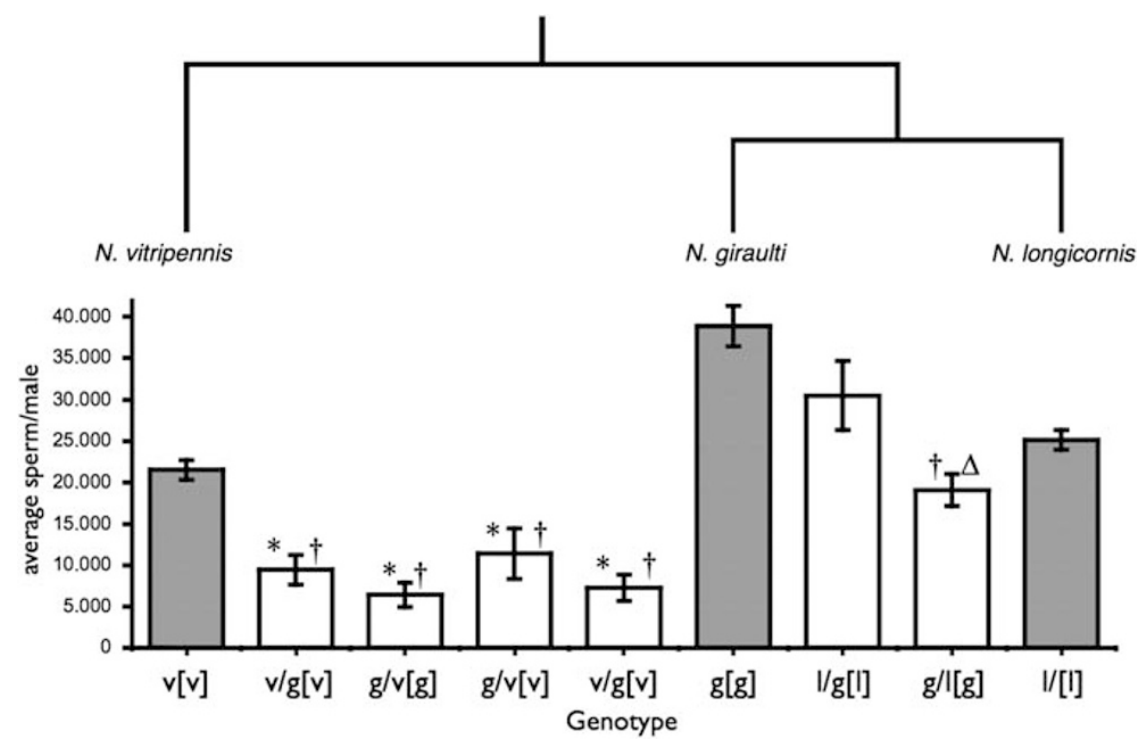

Figure 2 Average total sperm production per male in parental and F2 hybrid males. The phylogenetic relationship between Nasonia species is shown (top). Average sperm production per 2- to 3-day-old male is shown (bottom). Genotypes are given as maternal/paternal[cytoplasm]. Shaded bars are parental strains, and white bars hybrid crosses. *Significant difference from vitripennis, ( $\dagger$ ) significant difference from giraulti, $(\Delta)$ significant difference from longicornis. Error bars are s.e.m.

Table 1 List of behaviors scored during courtship observations

\begin{tabular}{ll}
\hline Move: & $\begin{array}{l}\text { General locomotion of each male was assessed during the first minutes of courtship observations. } \\
\text { Males that moved little were scored } 0 . \text { Males that moved slowly or infrequently were scored } 1 .\end{array}$ \\
& Males that moved quickly and frequently were scored 2.
\end{tabular}

prolonged developmental times. As Wolbachia normally prevent or severely reduce the production of hybrid females (Bordenstein et al., 2001), standard cured strains were used. These include a vitripennis strain, AsymC, and a longicornis strain, IV7R2. Two giraulti strains were used: a standard cured strain, RV2R, and another, R16A, that has the same nuclear genome introgressed into a vitripennis cytoplasm (Breeuwer and Werren, 1995). All strains are highly inbred, but do not suffer from serious inbreeding depression because Nasonia populations harbor few recessive deleterious mutations because of male haploidy and routine inbreeding (Werren, 1993). For crosses investigating hybrid sperm count, two lines (AsymCX and RV2RX) were used in place of AsymC and RV2R to facilitate future genetic characterization. These are derived from the original lines by additional inbreeding and are the lines used in the Nasonia genome sequencing.

The cytotypes of wasps are given in brackets. Cytotypes are inherited only from the mother. Cytotypes are designated with $[v],[g]$ or $[l]$ for vitripennis, giraulti and longicornis. No behavioral or other relevant differences were found between the two parental giraulti strains, and therefore they are pooled in all behavioral analyses.
Crosses between giraulti and longicornis were performed in both directions to produce F1 hybrid females with alternate cytotypes. F1 females of both cytotypes were produced in crosses between vitripennis and giraulti, but the potential influences of maternally encoded nuclear gene effects were controlled by crossing vitripennis males with either giraulti $[g]$ or giraulti $[v]$ females. Hybrid females were then given hosts as virgins to produce haploid recombinant F2 hybrid male offspring (only fertilized eggs produce female offspring) that were used in behavioral observations. Owing to male haploidy, recessive epistatic interactions affecting hybrid behavior or physiology will be expressed among F2 hybrid males.

\section{Courtship observations}

Males were collected as pupae and stored in groups $(\sim 8)$ in glass vials until eclosion. Eclosed males were removed without anesthesia and stored in groups $(\sim 4)$ in clean glass vials for 1 day. After 1 day, their courtship behavior was observed. Each male was placed in a clear $12 \times 75 \mathrm{~mm}$ glass vial with five virgin females. Females were no older than 3 days; to minimize the potential effects of female age variation, females of different ages were presented to each type of male in approximately equal numbers. 
Each male was observed for $15 \mathrm{~min}$, during which time we recorded whether the male followed, mounted, arrested, oriented on, displayed for and copulated with females (see Table 1). Each of these behaviors must be performed in order; that is, males have never been observed to skip one or more steps and successfully proceed to later steps (JH Werren, personal observation). Observed behaviors could have involved a single female or multiple females. Each behavior could be clearly scored with the naked eye.

\section{Sperm counts}

Virgin males were aged between 48 and $72 \mathrm{~h}$ after eclosion. Male reproductive tracts (testes, seminal vesicles, accessory glands) were dissected in TBST $(50 \mathrm{mM}$ Tris, $150 \mathrm{mM} \mathrm{NaCl}^{0.1 \%}$ Tween, $0.05 \% \mathrm{NaN}_{3}, \mathrm{pH} 7.5$ ) on clean depression well slides. For each male, one seminal vesicle was carefully removed and placed alone in a depression well with TBST. The remainder of the reproductive tract was transferred to a tube containing fixative (3.7\% formaldehyde in TBST). To count sperm, the single seminal vesicle was carefully opened with minuten pins and sperm liberated. The sperm and ruptured seminal vesicle were then transferred with $20 \mu \mathrm{l}$ TBST into a $0.7 \mathrm{ml}$ tube and vortexed for $30 \mathrm{~s}$ to evenly distribute the sperm. Sperm were then spotted onto a lysine-coated slide in eight $\times 2 \mu$ spots and allowed to adhere to the slide and air-dried for 10$15 \mathrm{~min}$ under mild heat (approximately $30^{\circ} \mathrm{C}$ ). The resulting spots were typically about $5 \mathrm{~mm}$ in diameter. Each sperm spot was then fixed with a drop of $3.7 \%$ formaldehyde in TBST and allowed to air-dry once again. Slides were washed in TBST and stained with $4^{\prime}, 6-$ diamidino-2-phenylindole (DAPI; $1 \mu \mathrm{g} \mathrm{ml}^{-1}$ ) for $30 \mathrm{~min}$ and mounted with ProLong mounting media (Invitrogen, Carlsbad, CA, USA) and covered with a coverslide. For each male, a minimum of three sperm spots (total $6 \mu \mathrm{l})$ were imaged with a Zeiss Z1 fluorescence microscope with $\times 10$ objective (Carl Zeiss, Thornwood, NY, USA) and captured with AxioVision software using a series of $8 \times 8$ overlapping images using both fluorescence (DAPI) and dark-field microscopy. Sperm nuclei (DAPI) were manually counted using the Axioimage measurement function. Overlapping or ambiguous sperm nuclei were resolved by viewing dark-field images. The total sperm count for each male was estimated as the total sperm counted in $6 \mu 1 \times 20 / 3$. A minimum of 10 males were analyzed for each parental line and hybrid cross (Figure 2). For each male analyzed, the second seminal vesicle and a single testis were similarly stained, mounted and imaged to confirm relative sperm production (seminal vesicle) and characterize testis development (Figures 3). Following the removal of the reproductive tract, males were decapitated and heads mounted on microscope slides on double-stick tape and the interocular distance was measured to assay body size.

\section{Familial patterns of hybrid courtship dysfunction}

In a separate experiment, hybrid behavioral sterility was characterized in more detail among F3 males derived from backcrossing F1 hybrid females with vitripennis cytotype to vitripennis males. Courtship was observed under a dissecting microscope of single males presented with three virgin vitripennis females and scored for courtship success. We proceeded to investigate whether a failure to display was inherited by focusing on a family in which abnormal courtship was observed. Some of the F3 males that failed to display had sisters produced by backcrossing their mother to vitripennis males. The sisters of one of these abnormal males were given hosts to produce F4 male offspring for further study. Ten subfamilies and 166 total males were studied.

\section{Sperm motility assay}

Sperm motility was also assessed cytologically. Before the sperm fixation described above, sperm motility was assessed following the rupture of seminal vesicle. Motile sperm was scored as present or absent.

\section{Statistics}

Behavior: Standard deviations for proportions were obtained by transforming proportions into angles $(\theta)$ through the arcsine square-root transformation. Variances of the angles were then calculated and used to determine standard deviations of $\theta$. Standard deviations were then back-transformed to give values in proportions for visual presentation in Figure 1.

When comparing the numbers of males among different genotype classes that performed a step in the courtship process, Fisher's exact tests were performed with a $2 \times 4$ contingency table using the numbers of males performing that behavior and numbers of males not performing the behavior. For the analysis of each courtship step, only those males that performed the previous step were included in the analysis rather than the total number of males observed. This was performed for two reasons. First, it reduces the chance of finding spurious significant results because of stochastic events during the entirety of the courtship process. Second, it allows us to infer at which specific steps in the process the genotype classes differ. For other data, $\chi^{2}$-tests were used, if appropriate. Fisher's exact tests were used in place of $2 \times 2 \chi^{2}$-tests whenever $N$ was less than 20 , or if $N$ was less than 100 and the smallest cell size was less than $4 . \chi^{2}$-Tests were used in all analyses that did not fit a $2 \times 2$ design.

Sperm counts: Mann-Whitney tests were used to compare the average total estimated sperm per male for each hybrid type compared with either parental line. Sperm counts and body size (interocular distance) were analyzed by comparing sperm count for large and small (above and below the median interocular distance) body size for pooled parental and pooled hybrid males.

\section{Results}

Hybrid male courtship function

Vitripennis $\times$ giraulti: In general, significant levels of behavioral sterility were observed in the older species pair hybrids, but not in the younger species pair hybrids. We first observed male courtship of hybrids and parents in the older species pair, vitripennis and giraulti. F2 vitripennis-giraulti hybrid males performed both early and late stages of courtship at reduced frequencies compared with parental vitripennis and giraulti males (Figure 1a). We describe the overall results for frequencies of males that follow, perform the display 

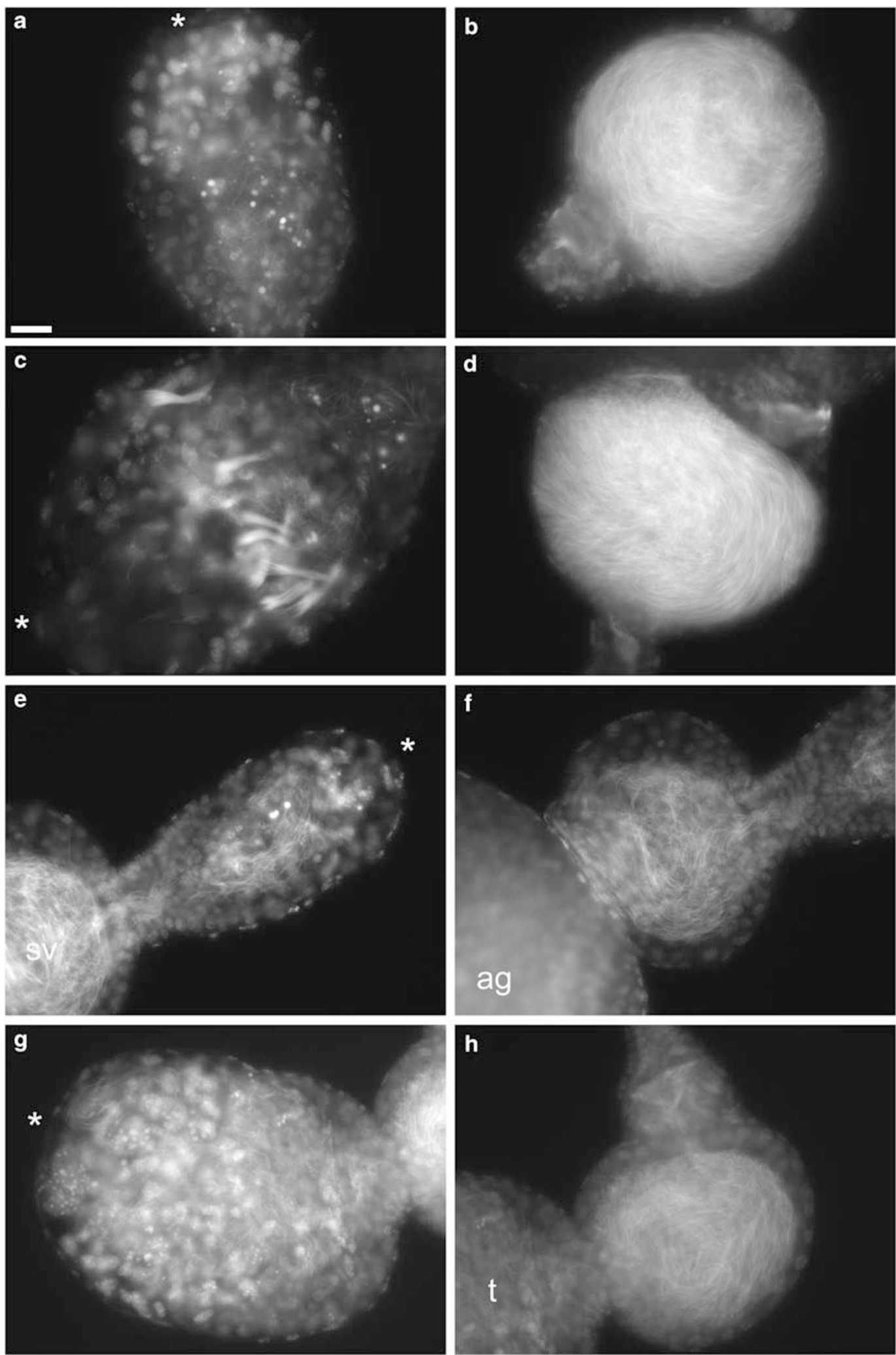

Figure 3 Testes (left) and seminal vesicles (right) from parental strains (a-d) and F2 hybrids (e, f). (a, b) N. vitripennis, (c, d) N. giraulti, (e, f) vitripennis-giraulti $\mathrm{F} 2(v),(\mathbf{g}, \mathbf{h})$ vitripennis-giraulti $\mathrm{F} 2(\mathrm{~g})$. Arrows indicate nuclei bundles from late stage spermatocysts. Asterisks indicate the apical end of testis. Scale bar $=20 \mu l$.

and copulate with either vitripennis or giraulti females, and consider the breakdown of individual stages of courtship.
Hybrids from the older species pair did not initiate the earliest stages of courtship as frequently as did the parental males. All pure species males followed both 
Table 2 Probabilities of performing courtship behaviors

\begin{tabular}{|c|c|c|c|c|c|c|c|c|}
\hline Cross male $\times$ female & $\mathrm{N}$ & Follow & Mount & Arrest & Orient & Display & Copulate & Overall \\
\hline \multicolumn{9}{|c|}{ (a) Courtship of vitripennis, giraulti, and vitripennis $\times$ giraulti hybrid males } \\
\hline Vitripennis $\times$ vitripennis & 33 & 1.00 & $1.00^{\mathrm{a}}$ & 1.00 & 1.00 & $1.00^{\mathrm{a}}$ & 1.00 & $1.00^{\mathrm{a}}$ \\
\hline Giraulti $\times$ vitripennis & 32 & 1.00 & $0.97^{\mathrm{a}, \mathrm{b}}$ & 0.97 & 1.00 & $1.00^{\mathrm{a}}$ & $0.70^{\mathrm{a}}$ & $0.66^{\mathrm{b}}$ \\
\hline F2 $(g) \times$ vitripennis & 48 & 0.88 & $0.62^{c}$ & 0.96 & 1.00 & $0.44^{\mathrm{b}}$ & $0.73^{\mathrm{a}}$ & $0.17^{\mathrm{c}}$ \\
\hline \multirow[t]{2}{*}{$\mathrm{F} 2(v) \times$ vitripennis } & 48 & 0.98 & $0.87^{\mathrm{b}}$ & 0.88 & 0.97 & $0.80^{c}$ & $0.82^{\mathrm{a}}$ & $0.48^{\mathrm{b}}$ \\
\hline & $P$-value & 0.015 & 0.000 & 0.124 & 1.000 & 0.000 & 0.002 & 0.000 \\
\hline Vitripennis $\times$ giraulti & 31 & $1.00^{\mathrm{a}}$ & $1.00^{\mathrm{a}}$ & 1.00 & 0.97 & $1.00^{\mathrm{a}}$ & $0.50^{\mathrm{a}}$ & $0.48^{\mathrm{a}}$ \\
\hline Giraulti $\times$ giraulti & 32 & $1.00^{\mathrm{a}}$ & $1.00^{\mathrm{a}}$ & 0.97 & 1.00 & $1.00^{\mathrm{a}}$ & $1.00^{\mathrm{b}}$ & $0.97^{\mathrm{b}}$ \\
\hline $\mathrm{F} 2(g) \times$ giraulti & 51 & $0.82^{\mathrm{b}}$ & $0.76^{\mathrm{b}}$ & 0.81 & 0.96 & $0.80^{\mathrm{b}}$ & $0.40^{\mathrm{a}}$ & $0.16^{\mathrm{a}}$ \\
\hline \multirow[t]{2}{*}{$\mathrm{F} 2(v) \times$ giraulti } & 45 & $0.93^{\mathrm{a}, \mathrm{b}}$ & $0.95^{\mathrm{a}, \mathrm{b}}$ & 0.95 & 1.00 & $0.82^{\mathrm{b}}$ & $0.42^{\mathrm{a}}$ & $0.29^{\mathrm{a}}$ \\
\hline & $P$-value & 0.004 & 0.000 & 0.021 & 0.453 & 0.001 & 0.000 & 0.000 \\
\hline \multicolumn{9}{|c|}{ (b) Courtship of longicornis, giraulti and longicornis $\times$ giraulti hybrid males } \\
\hline Giraulti $\times$ giraulti & 25 & 1.00 & 1.00 & 1.00 & 1.00 & 1.00 & 0.96 & 0.96 \\
\hline Longicornis $\times$ giraulti & 25 & 1.00 & 1.00 & 0.96 & 1.00 & 1.00 & 0.96 & 0.92 \\
\hline $\mathrm{F} 2(l) \times$ giraulti $i$ & 62 & 0.95 & 0.93 & 0.96 & 0.98 & 1.00 & 0.90 & 0.76 \\
\hline \multirow[t]{2}{*}{$\mathrm{F} 2(g) \times$ giraulti } & 47 & 0.98 & 0.96 & 1.00 & 0.98 & 0.93 & 0.93 & 0.79 \\
\hline & $P$-value & 0.676 & 0.464 & 0.559 & 1.000 & 0.087 & 0.881 & 0.157 \\
\hline Giraulti $\times$ longicornis & 21 & 0.95 & 0.95 & 1.00 & 1.00 & 1.00 & $0.42^{\mathrm{a}}$ & $0.38^{\mathrm{a}}$ \\
\hline Longicornis $\times$ longicornis & 21 & 1.00 & 1.00 & 1.00 & 1.00 & 1.00 & $0.95^{\mathrm{b}}$ & $0.95^{\mathrm{a}}$ \\
\hline $\mathrm{F} 2(l) \times$ longicornis & 37 & 0.92 & 1.00 & 0.97 & 1.00 & 1.00 & $0.55^{\mathrm{a}}$ & $0.49^{\mathrm{b}}$ \\
\hline \multirow[t]{2}{*}{$\mathrm{F} 2(\mathrm{~g}) \times$ longicornis } & 39 & 0.97 & 1.00 & 0.97 & 1.00 & 0.97 & $0.51^{\mathrm{a}}$ & $0.46^{\mathrm{a}}$ \\
\hline & $P$-value & 0.666 & 0.670 & 1.000 & 1.000 & 1.000 & 0.001 & 0.000 \\
\hline
\end{tabular}

The probabilities of transition to the next courtship step are shown below for parental and hybrid males. Probabilities are the numbers of males performing the current step/the number of males who performed the previous step. Also shown are Fisher's exact tests to determine if the four types of males differed in their abilities to complete the courtship step with a particular type female (Bonferroni correction, $\alpha=0.05$, $P$-values of 0.0083 or less are significant).

Bold values indicate significant differences. Different superscripts indicated significant difference.

vitripennis and giraulti females, but a significantly reduced proportion of $\mathrm{F} 2(g)$ hybrid males followed giraulti females (Fisher's exact test, $P<0.012$; Table 2). Hybrids followed vitripennis females only slightly less frequently (88-98\% of total males tested) than did pure species males. The frequencies at which males displayed also differed significantly among the four male types (Fisher's exact test, $P \leqslant 0.001$ ). When given vitripennis virgin females, all or nearly all wild-type vitripennis $(100 \%, N=33)$ and giraulti $(97 \%, N=32)$ males mounted and performed courtship displays within $15 \mathrm{~min}$. In contrast, hybrid F2(g) $(23 \%, N=48)$ and F2(v) $(59 \%$, $N=48$ ) males performed courtship displays at reduced frequencies. Nearly all vitripennis $(97 \%, N=31)$ and giraulti $(97 \%, N=32)$ males also displayed with giraulti females, whereas F2 $(g)(39 \%, N=51)$ and F2(v) $(69 \%$, $N=45)$ males displayed significantly less frequently with giraulti females (Fisher's exact test, $P \leqslant 0.001$ ).

F2 hybrid males also copulated with females at frequencies different from those of parental males. Copulation frequencies with vitripennis females ranged from $17 \%$ of total males for $\mathrm{F} 2(\mathrm{~g})$ males to $100 \%$ for vitripennis males. Differences among the four types of males in copulation frequencies with vitripennis females were highly significant (Fisher's exact test, $P=0.002$ ). Copulation frequencies with giraulti females were similarly reduced for hybrid males compared with parental males and ranged from $16 \%$ for F2 $(g)$ males to $97 \%$ for giraulti males $(P \leqslant 0.001)$. None of the males that failed to display were able to stimulate female receptivity or copulate, and therefore they were effectively completely sterile. Performance of a display did not guarantee copulation, though as many hybrid and interspecific males displayed but were rejected by females.

Figure 1a also reveals a strong cytoplasmic effect on performance of courtship behavior in F2 hybrid males. Hybrids with the giraulti cytoplasm were less likely to perform all behaviors. Only 39\% of total males tested displayed to giraulti females and $23 \%$ displayed to vitripennis females. In comparison, $58 \%$ of total F2(v) males displayed to vitripennis females, and $69 \%$ displayed to giraulti females. Both differences are highly significant $\left(\chi^{2}, P<0.005\right)$. Effects dependent on maternal nuclear genotype can be ruled out, because F1 hybrid mothers have the same nuclear genotype. These findings are complementary to those published by Breeuwer and Werren (1995), which showed that hybrid lethality is more severe among hybrids with the giraulti cytotype. It therefore appears that the males who survive nuclear-CI also suffer from nuclear-cytoplasmic interactions that affect their courtship abilities.

Typically, display and copulation occur only after a precise series of courtship behaviors have been completed by the male. Our observations allowed us to assess the specific stages at which hybrid courtship broke down. For each of six courtship behaviors, we compared the four types of males to find at which steps the frequencies of males performing the behavior differed, given that those males had completed the previous behavior. Correcting for multiple comparisons (Bonferroni correction $=0.0083$ ), significant differences attributable to hybrid behavioral sterility were found among the four classes of males in two or three courtship steps, depending on the female species (Table 2). When presented with vitripennis females, the male classes 
differed in their probability of mounting and displaying. These differences were due to hybrid-specific deficiencies, as giraulti males did not differ significantly from vitripennis males in their abilities to mount females (Fisher's exact test, $P=0.492$ ), and all vitripennis and giraulti males that oriented on vitripennis females displayed. When presented with giraulti females, the male classes differed in their probability of following females, as well as mounting and displaying. All vitripennis males followed, mounted and displayed when presented with giraulti females, so these differences cannot be attributed to interspecific differences. Among the males that displayed, the four classes also differed in their probability of copulating with giraulti females following courtship. All giraulti males mated with giraulti females, but only $50 \%$ of vitripennis males and $40-42 \%$ of hybrids males that displayed also copulated. This can be attributed to interspecific differences in the ability to stimulate female receptivity, because no significant difference was found among the hybrid classes and interspecific vitripennis males in the ability to copulate with giraulti females once they had completed the earlier steps (Fisher's exact test, $P>0.569$ ).

We also assessed the overall activity levels of males using a subjective three-level score. Hybrid males exhibited decreased locomotor activity compared with wild-type vitripennis and giraulti males. Vitripennis (mean $=1.9 \pm 0.22$ s.d.) and giraulti $(1.9 \pm 0.30)$ males did not differ in their mean scores or in the frequencies of males that scored 2 (normal movement) vs 1 (reduced movement) $\left(\chi^{2}=0.70,1\right.$ d.f., $\left.P=0.39\right)$, and no vitripennis or giraulti males scored 0 (no movement). Their movement scores were therefore pooled for comparisons to hybrids. F2 $(v)$ males had significantly lower movement scores $(1.5 \pm 0.56)$ than parentals $\left(\chi^{2}=92.5,2\right.$ d.f., $P<0.0005)$, and F2 $(g)$ males $(1.1 \pm 0.62)$ differed significantly from $\mathrm{F} 2(v)$ males $\left(\chi^{2}=7.59,2\right.$ d.f., $\left.P=0.023\right)$. In fact, $14 \%$ of F2 $(g)$ hybrid males showed little movement during the $15 \mathrm{~min}$ observation period. Therefore, we conclude that part of the failure of hybrids to successfully mate is due to reduced locomotor abilities, which may relate to nuclear-mitochondrial incompatibilities (Breeuwer and Werren, 1995; Niehuis et al., 2008).

Familial patterns of hybrid courtship dysfunction Courtship was observed by F3 males created by backcrossing F1 hybrid females with vitripennis cytotype to vitripennis males. When presented with three virgin vitripennis females, 9 of 66 males successfully mounted a female. Of the 57 males that mounted, 10 failed to display. The males that failed to display exhibited a variety of dysfunctions. Among males that mounted, some quickly dismounted without attempting to proceed with courtship. Some dismounted after failing to properly orient over the female's head, often after rotating several times while mounted. Most strikingly, some males proceeded to promptly orient and assume a position to display, only to pause for up to $3 \mathrm{~min}$ before either unsuccessfully attempting to copulate or simply dismounting. The tendency of some of these males to attempt to copulate without performing a display indicated that their dysfunction is specific to the display portion of courtship. These latter behaviors were not observed among parental males of either species, and are highly unusual based on many observations of courtship behavior of pure species males.

We then proceeded to investigate whether these syndromes (leading to a failure to display) were inherited by focusing on a family in which abnormal courtship was observed. Some of the F3 males that exhibited ablated courtship displays had sisters produced by backcrossing their mother to vitripennis males. The sisters of one of these abnormal males were given hosts to produce F4 male offspring for further study. Ten subfamilies and 166 total males were studied. Of these, $9.0 \%$ of the males observed failed to mount vitripennis females, and only $15.2 \%$ of males that mounted failed to display. The subfamilies differed in the frequency at which these behaviors were observed. In three of the ten subfamilies, all of the males displayed. In the other seven subfamilies, between 4.7 and $67 \%$ failed to court (test for differences among families, $\chi^{2}=42.7,9$ d.f., $\left.P<0.0005\right)$. These families are noteworthy because they suggest a heritable component to courtship dysfunction.

Longicornis $\times$ giraulti: Courtship behaviors of F2 hybrid males from the younger species pair (longicornis and giraulti) were less affected than those from the older species pair (Figure 1b; Table 2). The basic pattern of longicornis male courtship is similar to that of vitripennis and giraulti males, although aspects of the display differ (van den Assem and Werren, 1994; Beukeboom and van den Assem, 2002). All longicornis males followed both giraulti and longicornis females; all giraulti males followed giraulti females and all but one followed longicornis females. Longicornis males readily completed the intervening steps and displayed for both giraulti $(96 \%$ of total males) and longicornis (100\%) females, and giraulti males readily completed the intervening steps and displayed for longicornis (90\%) and giraulti (100\%) females. Therefore, little evidence of behavioral sterility was observed in the older species pair. These hybrid males followed both species females at high frequencies (92-98\% of total hybrid males tested). When presented with giraulti virgin females, F2 hybrids between longicornis and giraulti displayed slightly less frequently $(84-85 \%)$, but no statistical difference was found among the four male genotypes (Fisher's exact test, $P=0.087$ ). When presented with longicornis virgin females, hybrids had a slightly higher probability of courting (89-90\%), and no differences were found among the male genotypes (Fisher's exact test, $P=0.881$ ). No significant differences among longicornis, giraulti, F2 $(g)$ and F2 $(l)$ males were found for any step in courtship, except in copulation frequencies with longicornis females (Fisher's exact test, $P=0.001$ ). This last effect can be attributed to sexual isolation, rather than hybrid breakdown, because hybrids copulated at frequencies intermediate between interspecific and intraspecific males. Hybrid males did exhibit slightly reduced locomotor activity relative to longicornis and giraulti males (longicornis, $1.9 \pm 0.31$; giraulti, 1.9 $\pm 0.27 ; \mathrm{F} 2(g), 1.7 \pm 0.45 ; \mathrm{F} 2(l), 1.7 \pm 0.44)$. No hybrid or nonhybrid males scored 0 , but nonhybrids differed significantly in the frequency of males scoring 1 and 2 vs $\mathrm{F} 2(l)$ hybrids $\left(\chi^{2}=9.18,1\right.$ d.f., $\left.P=0.002\right)$ and F2 $(g)$ hybrids $\left(\chi^{2}=9.44,1\right.$ d.f., $\left.P=0.002\right)$. In conclusion, although these hybrids may suffer from slightly reduced locomotor abilities, no behavioral sterility was observed. 


\section{Spermatogenic fertility of hybrid males}

Spermatogenesis is functionally ameiotic in Nasonia, and female behaviors result in low levels of sperm competition. Therefore, models based on sterility evolving because of sexually antagonistic selection (Parker and Partridge, 1998) or meiotic drive (Hurst and Pomiankoski, 1991; Phadnis and Orr, 2009) seem not to apply. Figure 2 shows the average sperm count per male for parental and F2 hybrid males. Among the older species pair (vitripennis-giraulti), the average total sperm number per male was significantly lower than in either vitripennis or giraulti. Among the younger species pair (giraultilongicornis), only one of the hybrid types F2[g] was significantly lower than parental lines.

Cytological examinations of sperm within seminal vesicles (Figures $3 b, d, f$ and $h$ ) confirm the sperm count data. Males with high sperm counts had swollen seminal vesicles full of tightly packed sperm (see parental seminal vesicles, Figures $3 b$ and $d$ ). Examination of testes from the same male gives insight into the causes of lowered sperm counts in hybrid males. The 'normal' male with high sperm counts typically had either no remaining spermatocysts within the testes (Figure 3a) or a small number of late stage spermatocysts. These late stage cysts are easily distinguished by the tight bundle of mature sperm nuclei (Figure 3c). Few or no spermatocysts at earlier stages of development are seen in these 'normal' adult testes. This reflects the synchronization of spermatocyst development in Nasonia. Seminal vesicles from males with low sperm counts have noticeably fewer sperm (Figures $3 f$ and $h$ ). Low sperm counts in hybrid males appear to be associated with either the presence of numerous immature spermatocysts within the testis (Figures $3 \mathrm{~g}$ and $\mathrm{h}$ ), or abnormally small testis with no remaining cysts (Figures $3 \mathrm{e}$ and $\mathrm{f}$ ). Although the testes and seminal vesicles of vitripennis-giraulti hybrid males are easily distinguished from those of the parental strains, giraulti-longicornis hybrid males were indistinguishable from either parental type. The seminal vesicles were typically swollen and full of sperm, and the testes either contained only late stage spermatocysts or no remaining cysts.

There was a significant difference in sperm count between large and small males (above and below the median interocular distance) for pooled parental line males $(U=134.0, P=0.0306)$ or pooled $\mathrm{F} 2$ hybrid males $(U=53.0, P=0.0128)$. Variation in male size and sperm count within parental lines may partly have been due to differences in larval crowding. However, larval crowding should not be a factor for vitripennis-giraulti hybrid males, as hybrid incompatibilities lead to high levels of mortality in these crosses and larval densities are always far below normal.

The fertility of F2 hybrid males from vitripennis and giraulti crosses was previously shown on the basis of cytology (the presence of motile sperm) and female offspring production (Breeuwer and Werren, 1990). Similar results are verified here. All F2 [v] and F2 $[g]$ males dissected, and all produced motile sperm, as did each vitripennis and giraulti males.

Hybrids produced between the younger species pair also appear to make motile sperm. All the F2[g] and F2[l] hybrid and parental males examined produced at least some motile sperm. The spermatogenic fertility of both hybrids has also been shown on the basis of their ability to sire typical numbers of female offspring when mated to a single female (Bordenstein et al., 2001).

As spermatogenesis is normally completed or near completed in adult males, we examined testes from pupa from each of the above crosses. Testes at this stage are normally ovoid in shape with a slight narrowing at the apical end (Clark et al., 2008). Testes from parental lines and longicornis-giraulti F2 hybrids were all normal in shape (10/10 per line normal). Abnormal pupal testes from vitripennis-giraulti F2 hybrids were frequently observed. Frequently, the apical end of testes of males was malformed (abnormal testes observed in 15 of 40 males). Rather than the typical rounded apical end, F2 males had either an elongated and pointed apical end or a prominent bulge at the apical end of the testis. It is unclear what effect, if any, these have on hybrid male sperm production.

\section{Discussion}

The traditional 'Haldane's rule' scenario (Haldane, 1922) does not apply to Nasonia, as there are no sex chromosomes. However, Haldane's rule can be extended to haplodiploids. The disproportionate effect of X (or Z) chromosomes in the hybrid incompatibilities can be expanded to the entire haploid genome of hybrid Nasonia males. Owing to the largely recessive nature of hybrid incompatibilities, F2 hybrid males offer an excellent opportunity to study the basis of genetic incompatibilities (Koevoets and Beukeboom, 2009). However, the same fundamental processes involving the accumulation of genetic incompatibilities do apply. Further, the same forces that can apply to genetic incompatibilities such as adaptive divergence (Dodd, 1989), sexual selection (Parker and Partridge, 1998) and genetic conflict (Hurst and Pomiankoski, 1991) are likely to operate.

Hybrid spermatogenic sterility is clearly a common phenomenon, found in crosses among many species (Haldane, 1922; Coyne and Orr, 1998). This study represents one of only a few that also shows behavioral sterility in hybrid males. These findings came about incidentally in a study of species differences in courtship behavior, as did an example from Drosophila (Noor, 1997). This underscores the importance of extending speciation studies to include more aspects of an organism's ecology, physiology and behavior. A current concern in the study of speciation genetics is the question of which reproductive isolation mechanisms evolve first. These mechanisms are considered likely causes of speciation, rather than phenomena that evolved after speciation was complete (Dobzhansky, 1937). Previous studies on hybrid male fertility in Nasonia have overlooked the effects on sperm count in hybrid males (Beukeboom and van den Assem, 2001; Bordenstein et al., 2001). Low levels of spermatogenic problems among the hybrids were previously reported by Bordenstein et al. (2001). However, those estimates were based on qualitative and not quantitative measurements, and spermatogensis was not investigated in detail. In each hybrid cross, at least $95 \%$ of hybrid males from both species pairs were reported to produce some normal (motile sperm). Here, we also report motile sperm in each hybrid male type, but significant levels of defects in spermatogenesis, delayed spermatogenesis and significant reductions in sperm production. Nevertheless, most hybrid males 
produce at least some mature sperm, and this probably explains why hybrid males that successfully mate are also fertile when crossed with females. Such assays are typically based on whether the mated female produces any female offspring (that is, has received functional sperm). As only one female is usually tested per male in such experiments, they are unlikely to detect reductions in mature and motile sperm. Studies of male hybrid sterility rarely consider sperm count or the result of mating to multiple females, and therefore it is likely that reduced sperm count may occur in hybrid males from species pairs currently described as lacking a level of hybrid spermatogenic sterility.

These data suggest that behavioral hybrid sterility is currently a greater reproductive barrier between vitripennis and giraulti than are lowered hybrid sperm counts. The majority of vitripennis-giraulti hybrid males were unable to successfully copulate with parental females. Those that did copulate would likely have transferred at least some motile sperm. Mated to only one female, hybrid males may appear to have full spermatogenic fertility as seen in previous studies (Bordenstein et al., 2001). However, Nasonia typically have female-biased sex ratios and a single male is likely to mate with multiple females (Whiting, 1967; Drapeau and Werren, 1999). Under these conditions, lowered sperm count is likely a significant barrier to hybrid male fertility. Bordenstein et al. (2001) showed that Wolbachia-induced incompatibilities arose early during speciation in the Nasonia species complex, based on the level of Wolbachia incompatibility, F2 hybrid lethality, and premating isolation in the younger and older species pairs. The study also reported summary results of the behavioral sterility experiments, which show little behavioral sterility in the young species pair but significant levels in the older species pair. Here, we present a more complete analysis, which includes the results at each stage of courtship, as well as the results of both reciprocal crosses for each species pair. The earlier study had pooled the reciprocal crosses and only reported the results of the mount, court and copulate stages of courtship. Our study confirms that behavioral sterility arises later in the species divergences, as do increases in spermatogenic problems in hybrids, relative to the Wolbachia-induced incompatibility. Further, we find that there is little effect of cytoplasm (that is, mitochondrial background) on levels of behavioral sterility, as evidenced by similar patterns in the reciprocal crosses, but a strong effect of cytoplasm in the older species pair. This is consistent both with evidence of strong nuclearcytoplasmic incompatibilities affecting partial F2 hybrid lethality in the older species combination (Breeuwer and Werren, 1995; Niehuis et al., 2008; Werren et al., 2010), rapid evolution of Nasonia mitochondria (Oliveira et al., 2008) and rapid divergence between the species of nuclear genes that interact with mitochondria (Werren et al., 2010). Therefore, it appears that those males that survive hybrid incompatibilities in the older species pairs still suffer from nuclear-mitochondrial incompatibilities that may contribute to observed behavioral sterility.

Why does Nasonia differ from other known cases of insect speciation, in that in Nasonia hybrids behavioral sterility is greater than spermatogenic sterility? At least two major biological factors could influence the evolu- tion of hybrid sterility in Nasonia. First, Nasonia females are predominantly monandrous, mating only once (van den Assem et al., 1980a). This diminishes the role of sperm competition among males in the genus. In many other insect species, females are polyandrous, and can mate with a second male while still carrying sperm from a previous mating (Eberhard, 1996). In Drosophila, for example, this has promoted sperm competition and presumably the rapid evolution of sperm (Pitnick and Markow, 1994; Pitnick et al., 1995). If hybrid incompatibilities evolve as a by-product of sexual selection (Wu and Davis, 1993; Boake, 2002), then one could expect the breakdown of spermatogenesis to evolve more rapidly in taxa in which sperm competition is important. Indeed, a comparative study reveals that the speciation rate is roughly three times higher in polyandrous families than in monandrous families (Arnqvist et al., 2000). Although sperm competition may not be as relevant in Nasonia, the courtship displays of the three species have diverged substantially (van den Assem and Werren, 1994). Thus, the evolution of reproductive behavior, rather than reproductive physiology, could have a more important role in the evolution of hybrid incompatibilities in the genus. Indeed, the evolution of sexual behaviors may be of paramount importance in driving speciation. Certainly, the evolution of premating isolation is a primary effect of sexual divergence (reviewed by Coyne and Orr, 1998). A secondary effect may be that changes at loci controlling sexual behavior provide the raw materials for the evolution of postmating incompatibilities (Shaw, 1996; Ting et al., 2001; Boake, 2002; Shaw and Parsons, 2002).

A second difference between Nasonia and many other insects used in speciation studies is the genetic system and its effects on spermatogenesis. Similar to most Hymenoptera, Nasonia has a haplodiploid sex-determining system. Females are diploid and arise from fertilized eggs, whereas males are haploid and arise from unfertilized eggs. A chromosome-pairing hypothesis has been suggested as a possible cause of hybrid sterility (Forsdyke, 2000). The theory posits that hybrid sterility could result from meiotic problems caused by difficulties in pairing between structurally divergent chromosomes. Male haploidy rules out the possibility of such chromosomal effects on hybrid fertility, because meiosis in Nasonia does not involve synapsis or bivalent formation (White, 1973). Thus, only genic differences could influence hybrid male spermatogenic sterility in the genus. Support for the role of chromosome structure in speciation is weak compared with that for the genic hypothesis $(\mathrm{Wu}, 2001)$, but a role has not been ruled out. That Nasonia hybrid males have evolved behavioral sterility earlier than spermatogenic sterility is consistent with the predictions of the chromosome-pairing hypothesis described. However, the theory would also predict that Nasonia hybrid females would be subject to sterility, but they are not. Further investigation of speciation in haplodiploids may reveal which of these two explanations, if either, explain the observed patterns of hybrid incompatibilities in Nasonia. The chromosome-pairing hypothesis predicts that hybrid spermatogenic sterility would evolve slower in haplodiploid species. The sexual selection hypothesis predicts that hybrid spermatogenic sterility would be observed more frequently among polyandrous haplodiploid species than among monandrous haplodiploid species. 
Temporal aspects of the evolution of hybrid

\section{incompatibilities in Nasonia}

Comparison of hybrid incompatibilities in the younger species pair with the older species pair allows us to make inferences about the order in which the incompatibilities arose. Except for the Wolbachia-induced CI, strong postzygotic reproductive isolation has not yet evolved between giraulti and longicornis (Bordenstein et al., 2001). Hybrids are viable, behaviorally fertile and have slightly reduced sperm count in only one hybrid cross. The longer divergence time of vitripennis and giraulti has led to the evolution of strong hybrid behavioral sterility and partial hybrid inviability as well as significant reduction in hybrid sperm counts.

The courtship behavior of hybrids from the remaining pairing, vitripennis $\times$ longicornis, has been described elsewhere (Beukeboom and van den Assem, 2001, 2002). Although both longicornis-vitripennis and giraulti-vitripennis are 'older' species pairs, only the giraulti-vitripennis hybrid males display severe reductions in the ability to mate with either parental type. Longicornis-vitripennis hybrid males retain a 'well-organized' courtship display. These hybrid males display yet another trait. The males readily court and exhibit intermediate courtship phenotypes that are biased toward the phenotype of the grandpaternal species. That these males do not suffer from the behavioral sterility seen in giraulti-vitripennis hybrids suggests that the loci that contribute to the giraulti-vitripennis hybrid defects were substituted relatively recently, after the divergence of giraulti and longicornis. An analysis of longicornis-vitripennis hybrid spermatogenesis may similarly provide insights into the timing of the evolution of genes contributing to hybrid sperm count reductions, but was not within the scope of this study.

\section{Specificity and genetic architecture of hybrid sterility}

Of the three hypotheses for hybrid behavioral sterility outlined, general hybrid malaise and epistatic interactions between courtship genes are possible explanations for the phenotype observed in Nasonia hybrids. The performance of unattractive intermediate phenotypes is not a viable explanation, because most of the sterility results from a failure to perform courtship, not from an inability to stimulate female receptivity.

General malaise can apparently account for some of the observed courtship dysfunction observed in vitripennis $\times$ giraulti F2 hybrids. Hybrids show reduced locomotor activity relative to nonhybrids, and this could influence their ability to court females. Indeed, among hybrid F2 $[g]$ and F2[v] males, the frequency of courting differs among males in the three movement classes $\left(\chi^{2}=17.55,2\right.$ d.f., $P<0.0005)$. Males given a higher score for locomotor activity were more likely to display. Among those males that displayed, the frequencies of males that copulated did not differ significantly among the three movement classes $\left(\chi^{2}=5.31,2\right.$ d.f., $\left.P=0.070\right)$. However, a simple reduction in locomotion cannot explain the differences between hybrids and pure species in courtship performance. Males that scored zero in locomotor ability make up less than $10 \%$ of the sampled population. Among males that scored 1 or 2 , the correlation between courtship and locomotion score becomes nonsignificant $\left(\chi^{2}=2.90,1\right.$ d.f., $\left.P=0.089\right)$. In addition, more than $25 \%$ of hybrid males that successfully mounted females failed to perform ritualized courtship. This suggests that courtship defects are at least partially independent of defects that inhibit activity. This observation also rules out gross sensory defects as the sole cause of dysfunction, as they would prevent males from finding and identifying females. Further genetic data and studies of the phenomenon in Nasonia and other animals could shed light on this question, and it could facilitate a productive merger of behavioral and speciation genetics.

It appears that a portion of hybrid male behavioral sterility in Nasonia may be caused by negative epistatic interactions between courtship-specific genes. That hybrid behavioral sterility could be due to interactions between courtship specific genes is potentially interesting for the study of both speciation genetics and the genetics of courtship behavior. Also, if the same genes involved in the divergence of courtship behaviors are involved in behavioral sterility, it would lend indirect support to the sexual selection hypothesis (Boake, 2002).

Most studies of hybrid sterility concern defects leading to nonfunctional sperm from hybrid males (Ting et al., 1998; Masly et al., 2006; Phadnis and Orr, 2009). Few studies address lowered sperm count in hybrid males (Mihola et al., 2008). The lack of cases with low sperm count from hybrid males may be significant and reflect the evolution of genes involved in spermatogenesis or it may simply reflect the methodologies used to study hybrid male fertility. Studies of hybrid male fertility typically do not include sperm counts. A close examination of sperm counts from hybrid males may reveal previously overlooked fertility deficits in close species pairs. The reduction in sperm numbers but not in the sperm motility reported here may suggest that reductions in sperm production precede sperm motility defect evolution in hybrid males.

It is clear, from a cytological examination of the testes, that lowered sperm count in vitripennis-giraulti hybrids is accomplished in at least two different ways. Consistent with a general hybrid malaise model, some adult males with low sperm counts have testes containing spermatocysts at earlier stages of development, typically seen only in the testes from pupa (Clark et al., 2008). These males may simply be slow at sperm maturation. This would, however, severely affect male fitness as most mating opportunities occur shortly after emergence. Another cause of low sperm count appears to be overall production of fewer sperm. In some cases, adult males have produced few sperm and testes are devoid of developing sperm cysts (Figures $3 e$ and $\mathrm{f}$ ). It is unclear whether the development of spermatocysts was aborted early in the development in these males or few spermatocysts were produced. If the latter were true, a defect in spermatogonial stem cell function is an obvious candidate. Misshapen pupal testes from only vitripennisgiraulti F2 hybrid testes were frequently observed. The defects were at the apical testis end, which harbors the spermatogonial stem cells. How these defects relate to the reductions in hybrid sperm production is unknown.

Negative epistatic interactions between spermatogenesis genes are a likely cause of at least some of the decrease in hybrid male sperm counts. As previously outlined, sperm competition in Nasonia is likely far less important than in other model systems. Therefore, it is 
unclear which type of genes may be interacting to lead to low hybrid sperm counts. One candidate for negative epistasis may be genes regulating total sperm count in each species. There is a significant difference in total sperm count between each of the three parental lines (Mann-Whitney $U$-test-vitripennis vs giraulti: $U=0$, $P<0.0001$; giraulti vs longicornis: $U=2.0, P<0.0001$; vitripennis vs longicornis: $U=25.0, P=0.0375)$. This is likely due to, in part, differences in overall body size but may also reflect true differences between the species. It is currently difficult to explain the differences in total sperm numbers between the species. $N$. giraulti has the highest level of within-host mating and the highest level of inbreeding (Drapeau and Werren, 1999). Consequently, sperm competition may be expected to be the least significant in giraulti and could lead to the evolution of lower sperm counts. The data presented in this study are the opposite of this prediction, with giraulti having the highest sperm count of the three species. Different sex ratios in the different species may have led to differences in average lifetime matings per male (Drapeau and Werren, 1999). This may in turn select for differences in total sperm production in each species. The sperm counts for each species reported here are consistent with this hypothesis; however, more work is required to address this question.

Nasonia have rapidly evolving mitochondria (Oliveira et al., 2008), and nuclear-mitochondria interactions are important in embryonic hybrid breakdown within Nasonia hybrids (Breeuwer and Werren, 1995; Ellison et al., 2008). It is unclear how the rapid mitochondrial evolution and nuclear-mitochondria interactions contribute to behavioral or spermatogenic hybrid sterility. Impaired mitochondrial function may be contributing to general hybrid malaise and increasing both types of sterility. Mitochondria have several crucial roles in spermatogenesis (Fuller, 1993), and it is likely then that mitochondria divergence among Nasonia species has additional roles in spermatogenic hybrid breakdown in addition to malaise.

Nasonia hybrid males suffer behavioral sterility and significant reductions in sperm production but not sperm motility. The biology of this emerging model organism (haploid males, synchronized spermatogenesis, highly inbred lines) and recently developed genetic tools (genome sequences, microarrays, hybrid introgressions, RNAi) make this a very attractive system to now answer questions about the molecular basis of these hybrid phenotypes (Werren et al., 2010).

\section{Acknowledgements}

We thank Berend-Jan Velthuis for assistance during behavioral experiments, Lin Fan for assistance with statistical analysis, and Seth Bordenstein and Rhitoban Raychoudhury for providing useful criticisms of the paper. This work was supported by grants from the National Science Foundation (IBN-9876356) and National Institute of Health (R01 GM0700026-04).

\section{Conflict of interest}

The authors declare no conflict of interest.

\section{References}

Arnold ML (1997). Natural Hybridization and Evolution. Oxford University Press: New York.

Arnqvist G, Edvardsson M, Friberg U, Nilsson T (2000). Sexual conflict promotes speciation in insects. Proc Natl Acad Sci USA 97: 10460-10464.

Beukeboom L, van den Assem J (2002). Courtship displays of introgressed, interspecific Nasonia males: further investigations into the 'grandfather effect'. Behaviour 139: 1029-1042.

Beukeboom LW, van den Assem J (2001). Courtship and mating behaviour of interspecific Nasonia hybrids (Hymenoptera, Pteromalidae): a grandfather effect. Behav Genet 31: 167-177.

Boake CRB (2002). Sexual signaling and speciation, a microevolutionary perspective. Genetica 116: 205-214.

Bordenstein SR, Drapeau MD, Werren JH (2000). Intraspecific variation in sexual isolation in the jewel wasp Nasonia. Evolution 54: 567-573.

Bordenstein SR, O'Hara FP, Werren JH (2001). Wolbachiainduced incompatibility precedes other hybrid incompatibilities in Nasonia. Nature 409: 707-710.

Breeuwer JA, Werren JH (1990). Microorganisms associated with chromosome destruction and reproductive isolation between two insect species. Nature 346: 558-560.

Breeuwer JA, Werren JH (1995). Hybrid breakdown between two haploid species: the role of nuclear and cytoplasmic genes. Evolution 49: 705-717.

Campbell BC, Steffen-Campbell JD, Werren JH (1993). Phylogeny of the Nasonia species complex (Hymenoptera: Pteromalidae) inferred from an internal transcribed spacer (ITS2) and 28S rDNA sequences. Insect Mol Biol 2: 225-237.

Clark ME, Bailey-Jourdain C, Ferree PM, England S, Sullivan W, Windsor D et al. (2008). Wolbachia modification of sperm does not always require residence within developing sperm. Heredity 101: 420-428.

Coyne JA, Kim SY, Chang AS, Lachaise D, Elwyn S (2003). Sexual isolation between two sibling species with overlapping ranges: Drosophila santomea and Drosophila yakuba. Evolution 56: 2424-2434.

Coyne JA, Orr HA (1998). The evolutionary genetics of speciation. Phil Trans Roy Soc B 353: 287-305.

Coyne JA, Orr HA (2004). Speciation. Sinaur: Sunderland, MA, 276-281. pp

Darling DC, Werren JH (1990). Biosystematics of Nasonia (Hymenoptera-Pteromalidae) 2 species reared from birds nests in North America. Ann Entomol Soc Am 83: 352-370.

Davies N, Aiello A, Mallet J, Pomiankoski A, Silberglide RE (1997). Speciation in two neotropical butterflies: extending Haldane's rule. Proc Biol Sci 264: 845-851.

Dobzhansky T (1935). A critique of the species concept in biology. Phil Sci 2: 344-345.

Dobzhansky T (1937). Genetics and The Origin of Species. Columbia University Press: New York.

Dodd DMB (1989). Reproductive isolation as a consequence of adaptive divergence in Drosophila pseudoobscura. Evolution 43: 1308-1311.

Drapeau MD, Werren JH (1999). Differences in mating behaviour and sex ration between three sibling species of Nasonia. Evol Ecol Res 1: 223-234.

Eberhard WG (1996). Female Control: Sexual Selection by Cryptic Female Choice. Princeton University Press: Princeton.

Ellison CK, Niehuis O, Gadau J (2008). Hybrid breakdown and mitochondrial dysfunction in hybrids of Nasonia parasitoid wasps. I Evol Biol 21: 1844-1851.

Forsdyke DR (2000). Haldane's rule: hybrid sterility affects the heterogametic sex first because sexual differentiation is on the path to species differentiation. J Theor Biol 204: 443-452.

Fuller MT (1993). Spermatogenesis. In: Bates MaA, A.R. (ed). The Development of Drosophila melanogaster. Cold Spring Harbor Press: Cold Spring Harbor, NY. pp 71-147. 
Good JM, Handel MA, Nachman MW (2008). Asymmetry and polymorphism of hybrid male sterility during the early stages of speciation in house mice. Evolution 62: 50-65.

Grant PR, Grant BR (1992). Hybridization in bird species. Science 256: 193-197.

Haldane JBS (1922). Sex ratio and unisexual sterility in hybrid animals. J Genet 12: 101-109.

Hatfield T, Schluter D (1996). A test for sexual selection on hybrids of two sympatric sticklebacks. Evolution 50: 2429-2434.

Hatfield T, Schluter D (1999). Ecological speciation in sticklebacks: environment-dependent hybrid fitness. Evolution 53: 866-873.

Holmes HB (1974). Patterns of sperm competition in Nasonia vitripennis. Can I Genet Cytol 16: 789-795.

Hurst LD, Pomiankoski A (1991). Causes of sex ratio bias may account for unisexual sterility in hybrids: a new explanation of Haldane's rule and related phenomena. Genetics 128: 841-858.

Jachmann F, van den Assem J (1996). A causal ethological analysis of the courtship behaviour of an insect (the parasitic wasp Nasonia vitripennis, Hym., Pteromalidae. Behavior 133 1051-1075.

Koevoets T, Beukeboom LW (2009). Genetics of postzygotic isolation and Haldane's rule in haplodiploids. Heredity 102: 16-23.

Leonard JE, Boake CR (2008). Associations between male courtship and female polyandry in three species of wasp, Nasonia (Hymenoptera: Pteromalidae). Anim Behav 76: 637-647.

Masly JP, Jones CD, Noor MA, Locke J, Orr HA (2006). Gene transposition as a cause of hybrid sterility in Drosophila. Science 313: 1448-1450.

Mayr E (1942). Systematics and the Origin of Species. Columbia University Press: New York.

Mihola O, Trachtulec Z, Cestmir V, Schimenti JC, Forejt J (2008). A mouse speciation gene encodes a meiotic histone $\mathrm{H} 3$ methyltransferase. Science 323: 373-375.

Niehuis O, Judson AK, Gadau J (2008). Cytonuclear genic incompatibilities cause increased mortality in male F2 hybrids of Nasonia giraulti and $N$ vitripennis. Genetics 178: 413-426.

Noor MA (1997). Genetics of sexual isolation and courtship dysfunction in male hybrids of Drosophila pseudoobscura and Drosophila persimilis. Evolution 51: 809-815.

Oliveira DC, Raychoudhury R, Lavrov DV, Werren JH (2008). Rapidly evolving mitochondrial genome and directional selection in mitochondrial genes in the parasitic wasp Nasonia (Hymenoptera: Pteromalidae). Mol Biol Evol 25: 2167-2180.

Parker GA, Partridge L (1998). Sexual conflict and speciation. Philos Trans R Soc London B Biol Sci 353: 261-274.

Pashley DP, Martin JA (1987). Reproductive incompatibility between host strains of the fall armyworm (Lepidoptera, Noctuidae). Ann Entomol Soc Am 80: 731-733.

Pennypacker MI (1958). The chromosomes of the parasitic wasp, Mormoniella vitripennis. I In spermatogenesis of haploid and diploid males. Arch Biol 69: 483-495.

Phadnis N, Orr HA (2009). A single gene causes both male sterility and segregation distortion in Drosophila hybrids. Science 323: 376-379.

Pitnick S, Markow TA (1994). Large-male advantages associated with costs of sperm production in Drosophila hydei, a species with giant sperm. Proc Natl Acad Sci USA 91: 9277-9281.
Pitnick S, Spicer GS, Markow TA (1995). How long is a giant sperm? Nature 375: 109.

Price DK, Boake CRB (1995). Behavioral reproductive isolation in Drosophila silvestris, D. heteroneura, and their F1 hybrids (Diptera, Drosophilidae). J Insect Behav 8: 595-616.

Raychoudhury R, Desjardins CA, Buellesbach J, Loehlin DW, Grillenberger BK, Beukeboom L et al. (2010). Behavioural and genetic characteristics of a new species of Nasonia. Heredity (doi:10.1038/hdy.2009.147).

Schluter D (1995). Adaptive radiation in sticklebacks-tradeoffs in feeding performance and growth. Ecology 76: 82-90.

Schluter D (2001). Ecology and the origin of species. Trends Ecol Evol 16: 372-380.

Shaw KL (1996). Polygenic inheritance of a behavioral phenotype: interspecific genetics of song in the Hawaiian cricket genus Laupala. Evolution 50: 256-266.

Shaw KL, Parsons YM (2002). Divergence of mate recognition behavior and its consequences for genetic architectures of speciation. Am Nat 159: S61-S75.

Stratton GE, Uetz GW (1986). The inheritance of courtship behavior and its role as a reproductive isolating mechanism in 2 species of Schizocosa wolf spiders (Araneae, Lycosidae). Evolution 40: 129-141.

Ting CT, Takahashi A, Wu C-I (2001). Incipient speciation by sexual isolation in Drosophila: concurrent evolution at multiple loci. Proc Natl Acad Sci USA 98: 6709-6713.

Ting CT, Tsaur SC, Wu ML, Wu CI (1998). A rapidly evolving homeobox at the site of a hybrid sterility gene. Science 282: 1501-1504.

Vamosi SM, Schluter D (1999). Sexual selection against hybrids between sympatric stickleback species: evidence from a field experiment. Evolution 53: 874-879.

van den Assem J, Gijswijt MJ, Nubel BK (1980a). Observations on courtship strategies and mating strategies in a few species of parasitic wasps (Chalcidoidae). Neth J Zool 49: 209-227.

van den Assem J, Jachmann F, Simbolotti P (1980b). Courtship behaviour of Nasonia vitripennis (Hym. Pteromalidae): some qualitative experimental evidence for the role of pheromones. Behavior 75: 301-307.

van den Assem J, Werren JH (1994). A comparison of the courtship and mating-behavior of three species of Nasonia (Hymenoptera, Pteromalidae). J Insect Behav 7: 53-66.

Werren JH (1993). The evolution of inbreeding in haplodiploid populations. In: Thornhill NW (ed). The Natural History of Inbreeding and Outbreeding. University of Chicago Press: Chicago. pp 42-59.

Werren JH, Richards S, Desjardins CA, Niehuis O, Gadau J, Colbourne JK et al (2010). Functional and evolutionary insights from the genomes of three parasitoid Nasonia species. Science 327: 343.

White MJD (1973). Animal Cytology and Evolution. Cambridge University Press: Cambridge.

Whiting AR (1967). The biology of the parasitic wasp Mormoniella vitripennis [=Nasonia brevicornis $]$ walker). Q Rev Biol 42: 333-406.

Wu C-I (2001). The genic view of the process of speciation. J Evol Biol 14: 851-865.

Wu C-I, Davis AW (1993). Evolution of postmating reproductive isolation - the composite nature of Haldane's rule and its genetic bases. Am Nat 142: 187-212.

Yamamoto D, Jallon JM, Komatsu A (1997). Genetic dissection of sexual behavior in Drosophila melanogaster. Ann Rev Entomol 42: 551-585. 